\title{
QUENCH PERFORMANCE OF SIX SIMILAR 17 m-LONG, 40 mm-APERTURE
}

\section{SSC MODEL DIPOLES•}

P. Wanderer and E. Willen

Accelerator Development Departmcit

Magnet Division

Brookhaven National Laboratory

Upton, New York 11973

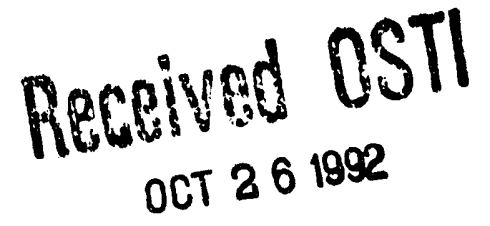

OCT 261992

\section{SUMMARY}

The quench performance of the final six $17 \mathrm{~m}$-long, $40 \mathrm{~mm}$-aperture SSC model dipoles made at Brookhaven National Laboratory is presented in summary form. The six magnets are of similar construction, except for two features: (1) the copper-tosuperconductor ratio of the inner cable (either $1.3: 1$ or $1.5: 1$ ) and (2) the axial preload at 4.35K. The inner coil quench performance does not appear to be correlated with the copper-to-superconductor ratio. There does appear to be a correlation between the outer coil quench performance and the cold axial preload.

\section{INTRODUCTION}

The construction of the final six full-length $40 \mathrm{~mm}$-aperture Collider dipoles at BNL was intended, among other things, to test the effect of the inner coil copper-tosuperconductor ratio on quench performance. The first three magnets, DC0201 - DC0203, had Cu:S.C. = 1.5:1 and the last three, DC0204 - DC0206, had Cu:S.C. = 1.3:1. The stability of cable in short-sample measurements has been found to be dependent on the $\mathrm{Cu}: \mathrm{SC}$ ratio. ${ }^{1}$ In other respects the magnets were intended to be alike, with axial and azimuthal preload in operation up to $6.5 \mathrm{kA}(6.6 \mathrm{~T})$. Construction details pertinent to this note are listed in Table I. The remaining construction features are described more fully elsewhere.3.

First, this note examines the quench performance of the inner coils. The quench performance of the magnets is shown in Figs. $1-6$. All of the magnets achieved a plateau at $4.35 \mathrm{~K}$, with the plateau quenches originating in the inner coil. Four of the magnets quenched repeatedly in the pole turn (turn 16), indicating conductor limited quenches. For these magnets, the ratio of the conductor limited quench current, $\mathrm{I}_{\mathrm{CL}}$, to the quench current

This work supported by the U.S. Department of Energy. 
estimated from short-sample tests, $I_{s s}$, is tallied in Table II. In two of the magnets, the plateau quenches originated in turns near the pole turn as noted in Table II. For these magnets, the data yield only a limit on the ratio $\mathrm{I}_{\mathrm{Cz}} / \mathrm{I}_{\mathbf{s s}}$. The limit is probably $1 \%-2 \%$ below the actual value of the ratio. This uncertainly limits the accuracy of the comparison to about $2 \%$, which is comparable to the uncertainty from other sources such as magnet temperature and short-sample measurements. (The three magnets made with Cu:S.C. = 1.3:1 all contain cable from the same spool; $\mathrm{I}_{\mathrm{CI}} / \mathrm{I}_{\mathrm{ss}}$ varies $1 \%$ in this set.) Within this $2 \%$ uncertainty, $\mathrm{I}_{\mathrm{CL}} / \mathrm{I}_{\mathrm{ss}}$ shows no dependence on the Cu:S.C. ratio.

Another approach to testing for effects of the Cu:S.C. ratio is to count the number of inner coil training quenches. This enumeration can be broken into three parts: initial quenching, quenching after a thermal cycle, and quenching at low tempeerature. (Outer coil quenches have been ignored for this exercise.) In the initial quench testing, one of the three magnets in each group has no training quenches and the other two do. The total number of training quenches for each group of three magnets (two for the magnets with Cu:S.C. = 1.5:1, four for the magnets with Cu:S.C. $=1.3: 1$ ) is small and not significantly different for the two groups. After the thermal cycle, the two groups have the same performance (one magnet with no retraining, two magnets with one retraining quench each). At low temperature, all three magnets with Cu:S.C. $=1.5: 1$ reach plateau with little additional training as does the one magnet (DC0206) with Cu:S.C. $=1.3: 1$ whose low temperature performance was not limited by the outer coil. In all, no significant difference is found between the number of training quenches in the two groups of magnets.

When the magnets were tested, quench origins in the outer coil were found in four of the magents. A careful review of the construction features (Table I) and quench performance (Table II) was made. The experiment with magnet DCO201, where outer coil quenches were observed after the end preload was reduced, coupled with experience with the $1.8 \mathrm{~m}$-long, $50 \mathrm{~mm}$-aperture magnets, which had improved quench performance as a result of increasing the end preload, "suggested that increasing the end preload might help. Consequently, the room temperature end preload in the last magnet, DC0206, was increased significantly. No quenches occurred in the outer coils of this magnet. A review of the outer coil quenches and end loading of these magnets shows a simple correlation: magnets with end preload at $4.35 \mathrm{~K}$ of $5600 \mathrm{lbs}$. or more do not quench in the outer coil; those with cold end preload of $2000 \mathrm{lbs}$. or less do. ${ }^{5}$

In addition to the warm end preload, two factors influenced the cold end preload. First, the interface between the yoke and collars was changed due to the addition of 3 mil shims after magnet DC0201. Second, the yoke packing factor was increased for the last four magnets. The combination of these two changes clearly influenced the axial preload during cooldown. The DC0201 end preload increased $5600 \mathrm{lbs}$. during cooldown, whereas the largest increase in the later magnets was $200 \mathrm{lbs}$., and most lost significantly. The large increase in the warm end preload of DC0206 compensated for the observed cooldown loss in the magnets with yoke-collar shims and extra laminations.

\section{DISCLAIMER}

\footnotetext{
This report was prepared as an account of work sponsored by an agency of the United States Government. Neither the United States Gnvernment nor any agency thereof, nor any of their employees, makes any warranty, express or implied, or assumes any legal liability or responsibility for the accuracy, completeness, or usefulness of any information, apparatus, product, or process disclosed, or represents that its use would not infringe privately owned rights. Reference herein to any specific commercial product, process, or service by trade name, trademark, manufacturer, or otherwise does not necessarily constitute or imply its endorsement, recommendation, or favoring by the United States Government or any agency thereof. The views and opinions of authors expressed herein do not necessarily state or reflect those of the United States Goyernment or any agency thereof.
} 


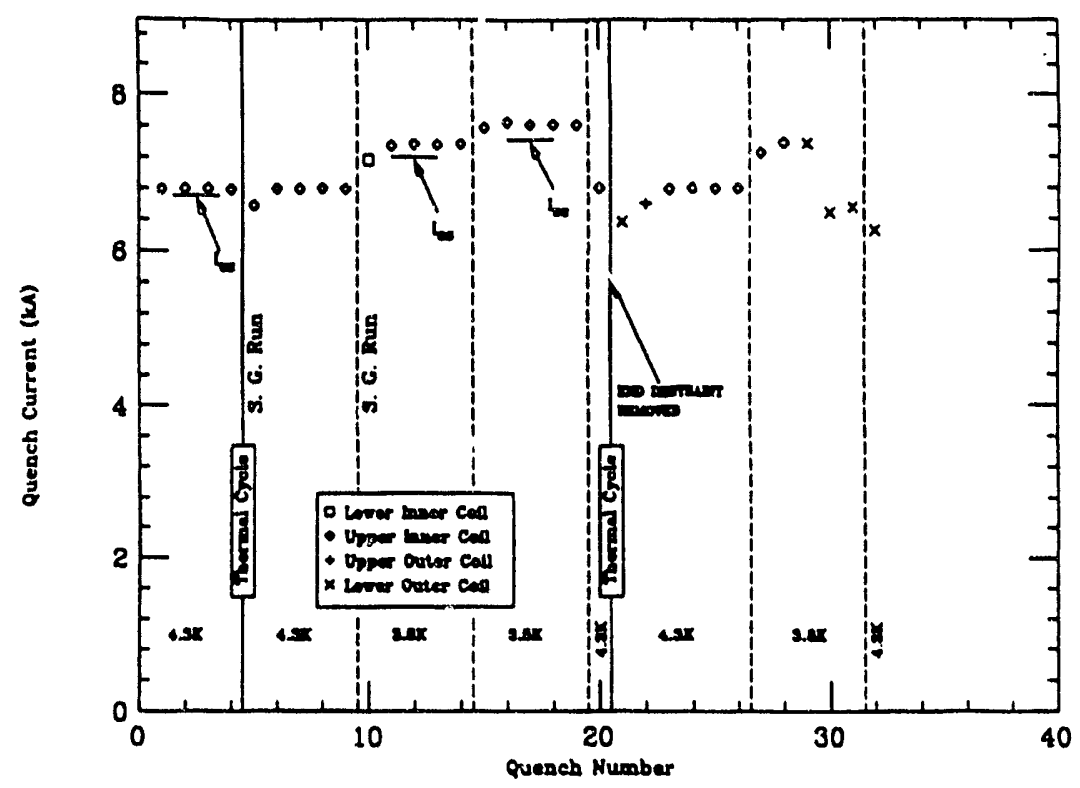

Figure 1. Quench history for magnet DC0201. This magnet was conditioned by ramping three times to $6.8 \mathrm{kA}$ at $3.5 \mathrm{~K}$ before the first quench.

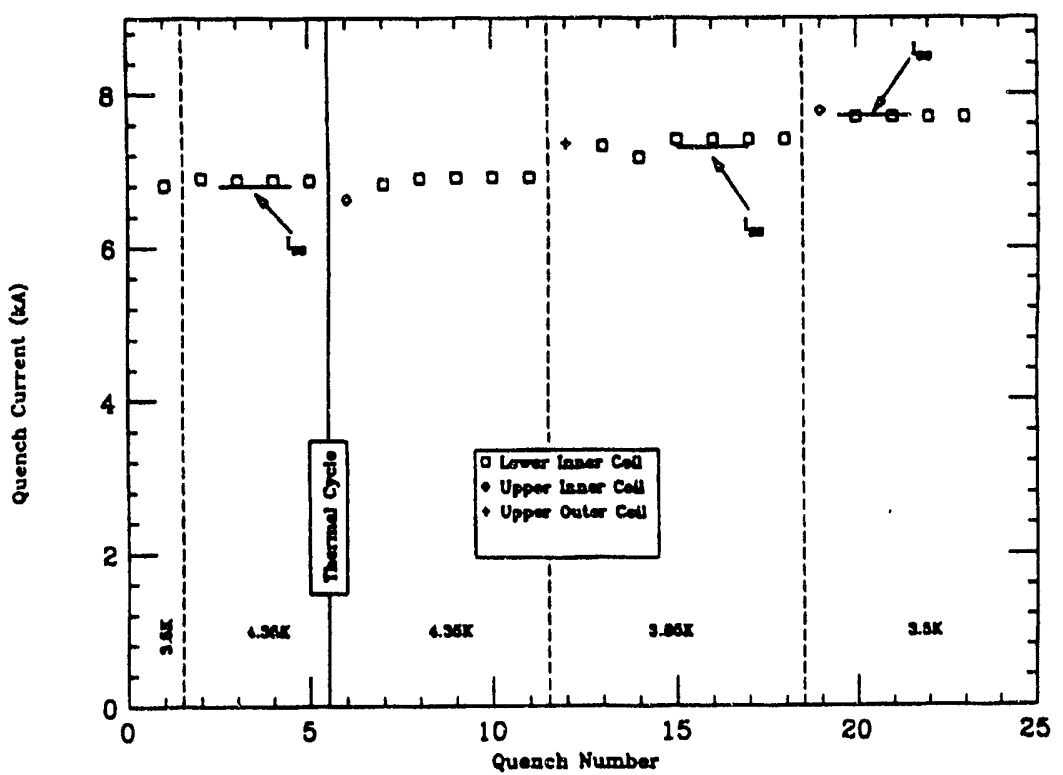

Figure 2. Quench history for magnet DC0202 


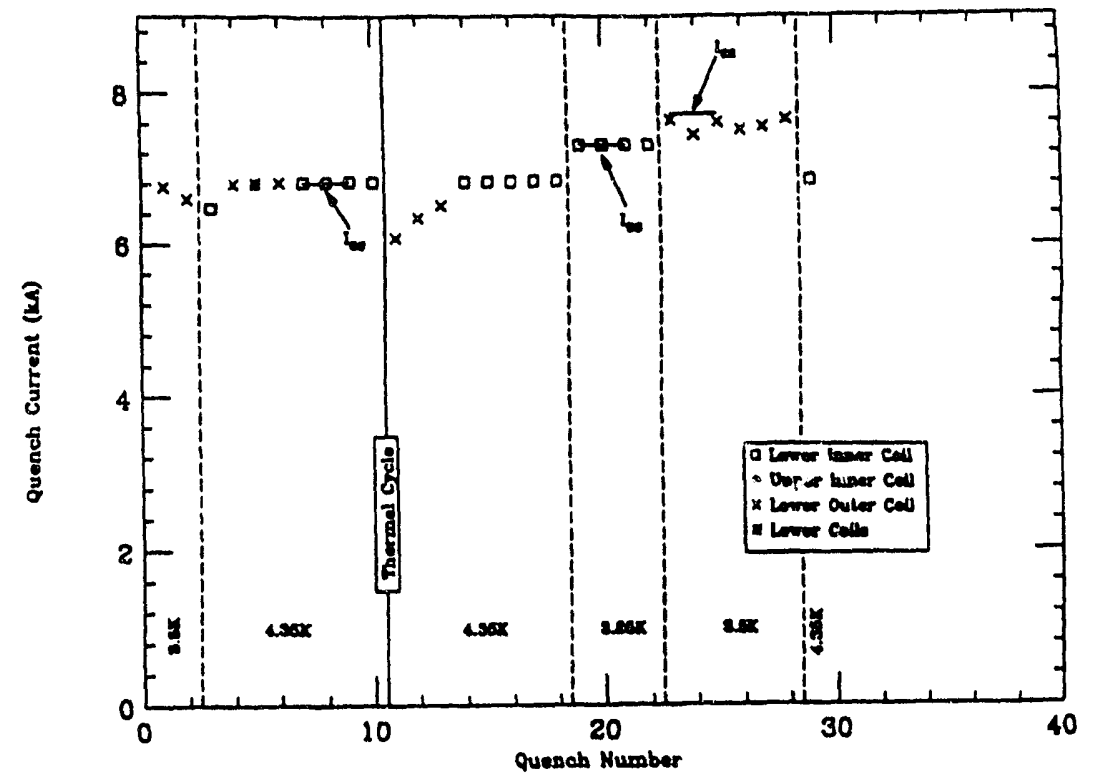

Figure 3. Quench history for magnet DC0203.

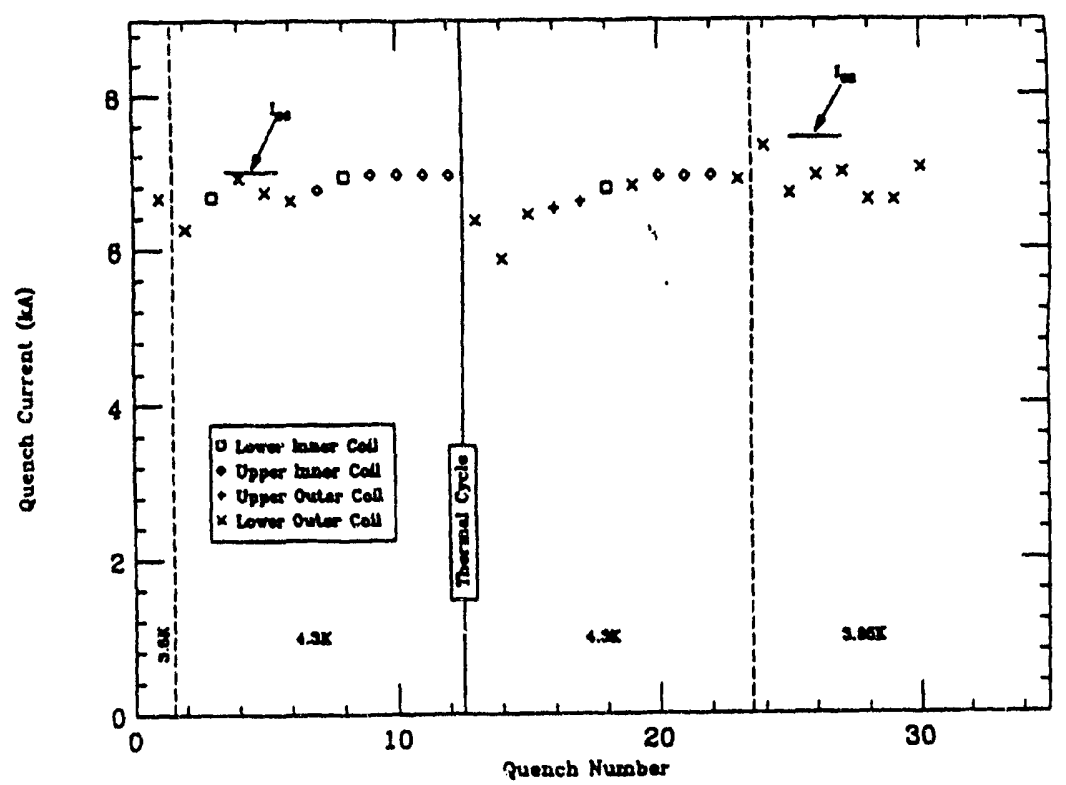

Figure 4. Quench history for magnet DC0204. 


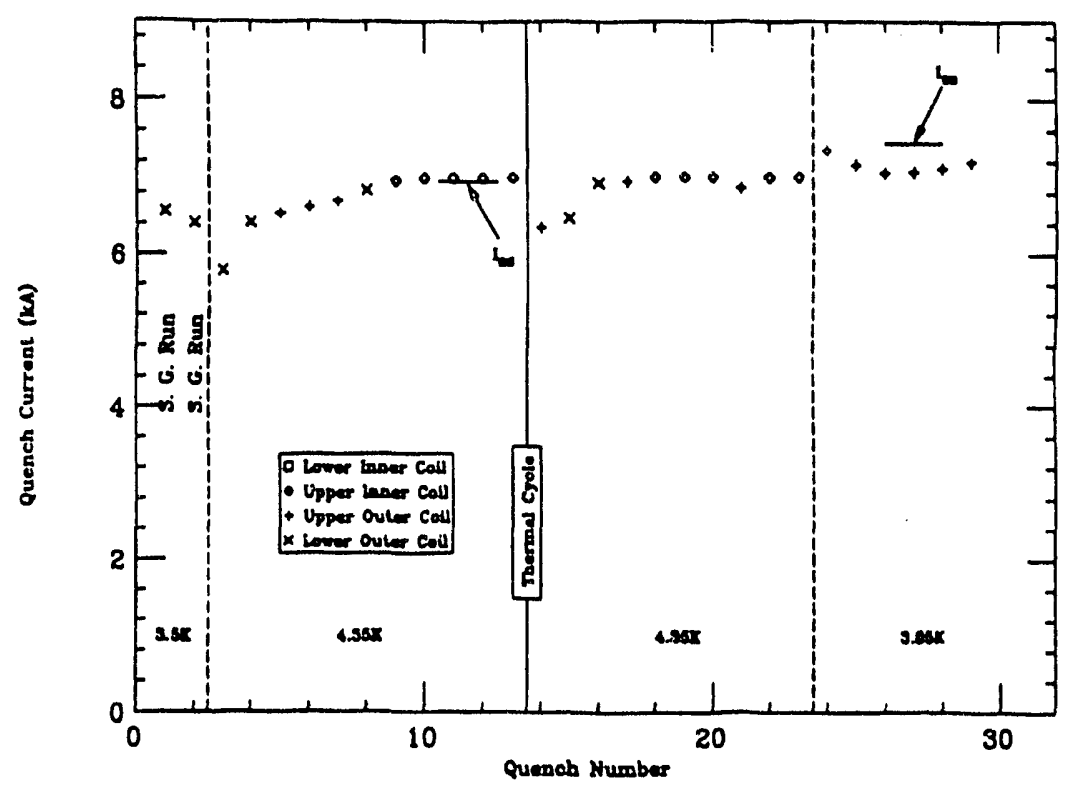

Figure 5. Quech history for magnet DC0205.

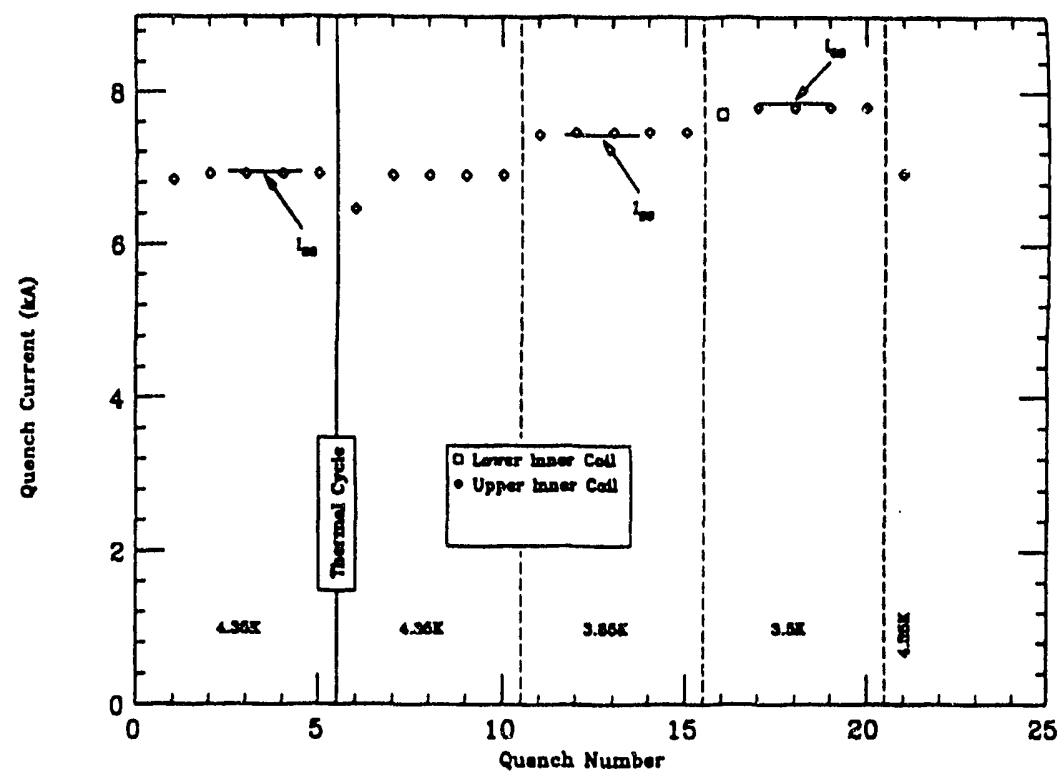

Figure 6. Quench history for magnet DC0206. This magnet was conditioned by ramping three timies to $6.8 \mathrm{kA}$ at $3.5 \mathrm{~K}$ before the first quench. 
Table I. Magnet Construction Features

\begin{tabular}{|c|c|c|c|c|c|c|c|c|c|c|}
\hline \multirow[b]{2}{*}{ Magnet } & \multicolumn{2}{|c|}{ Cable } & \multirow[b]{2}{*}{$\mathrm{I}_{\mathrm{C}}(7 \mathrm{~T})$} & \multirow[b]{2}{*}{$\begin{array}{l}I_{s s}(\mathrm{~A}) \\
4.35 \mathrm{~K} \\
\end{array}$} & \multicolumn{2}{|c|}{$\begin{array}{c}\text { Cable } \\
\text { FG } \\
\text { Epoxy } \\
\text { Content } \\
(\%)\end{array}$} & \multirow[b]{2}{*}{$\begin{array}{l}\text { Cu:SC } \\
\text { Inner }\end{array}$} & \multicolumn{2}{|c|}{ Yoke Weight (lbs.) } & \multirow[b]{2}{*}{$\begin{array}{c}\text { No. of } \\
\text { Laminations } \\
\text { Added }\end{array}$} \\
\hline & Inner & Outer & & & I & 0 & & $\begin{array}{l}\text { Before } \\
\text { extra } \\
\text { Lams. }\end{array}$ & $\begin{array}{c}\text { After } \\
\text { extra } \\
\text { Lams. }\end{array}$ & \\
\hline DC0201 & I-B0310 & S-2071 & 7851 & 6738 & 24 & 24 & $1.5: 1$ & 11295.06 & 11295.06 & 0 \\
\hline DC0202 & I -5264 & I-B0359 & 7791 & 6800 & 20 & 24 & $1.5: 1$ & 11306.20 & 11306.20 & 0 \\
\hline DC0203 & I-5264 & I-B0359 & 7791 & 6800 & 20 & 24 & $1.5: 1$ & 11306.76 & 11315.36 & 7 \\
\hline DC0204 & S-2346 & I-B0397 & 8368 & 6944 & 20 & 24 & $1.3: 1$ & 11307.64 & 11315.24 & 7 \\
\hline DC0205 & S-2346 & $\begin{array}{l}\text { I-B0359 } \\
\text { I-B0397 }\end{array}$ & 8368 & 6944 & 20 & 24 & 1.3:1 & 11309.29 & 11321.19 & 11 \\
\hline DC0206 & S-2346 & $\begin{array}{l}\text { I-B0640 } \\
\text { I-B0641 }\end{array}$ & 8368 & 6944 & 20 & 20 & $1.3: 1$ & 11309.39 & 11314.79 & 5 \\
\hline
\end{tabular}

NOTES:

1. 201: No shims; 202-206: 3 mil shims at poles between collar and yoke.

2. 202, 203, 205, 206: Increased end force before test.

3. 203: Asymmetry of one outer coil wedge reversed.

4. 201, 204: Bridge, via RTV/weld of end tubes, between end plate and yoke.

5. This series of magnets used low carbon steel spacers between blocks rather than stainless steel spacers

6. as used in earlier magnets.

6. The yoke design specified a fixed weight of steel over the specified yoke length. When spaces between yoke blocks developed because of more compact yoke blocks, extra laminations were mistakenly added in the later magnets, giving a higher yoke density in these magnets.

Table II. Magnet Performance.

\begin{tabular}{|c|c|c|c|c|c|c|c|c|c|c|c|}
\hline \multirow[b]{2}{*}{ Magnet } & \multicolumn{3}{|c|}{ Cold Azimuchal Prestress } & \multicolumn{4}{|c|}{ Total End Force (lbs.) } & \multicolumn{2}{|c|}{$\begin{array}{c}\text { No. of } \\
\text { Training } \\
Q\end{array}$} & \multirow[b]{2}{*}{$I_{c L}(A)$} & \multirow[b]{2}{*}{$I_{a} / I_{s a}$} \\
\hline & $\begin{array}{c}\sigma, \text { Inner, } \\
I=0 \\
\text { (PSI) } \\
\end{array}$ & $\begin{array}{c}0 . \text { Outer, } \\
I=0 \\
\text { (PSI) } \\
\end{array}$ & $\begin{array}{c}I^{2} \text { for } \\
\sigma, \text { Inner }=0 \\
(\mathbb{K A})^{2}\end{array}$ & $\begin{array}{c}\text { After } \\
\text { Welding }\end{array}$ & $\begin{array}{c}\text { Cold, } \\
\text { Before } 9\end{array}$ & $\begin{array}{l}\text { Cold, } \\
\text { After Q }\end{array}$ & $\begin{array}{c}\text { Force at } \\
L^{2}=40(\mathrm{kA})^{2}\end{array}$ & $\underline{I}$ & o & & \\
\hline DC0201 & 4000 & 3800 & 27 & 1400 & 5600 & 7200 & 9000 & 0 & 0 & 6788 & 1.007 \\
\hline DCO202 & 3220 & 2970 & 28 & 3100 & 1600 & 4130 & 6800 & 1 & 0 & $>6899$ & $>1.015$ \\
\hline $\mathrm{DC0203}$ & 2340 & 4130 & 22 & 3690 & 1910 & 3060 & 5600 & 1 & 5 & $>6803$ & $>1.000$ \\
\hline DC0204 & 3000 & 3800 & 25 & 1600 & 1800 & 3600 & 6000 & 3 & 5 & 6961 & 1.002 \\
\hline DC0206 & 2820 & 3900 & 25 & 2800 & 2000 & 2800 & 4000 & 0 & 8 & 6985 & 1.006 \\
\hline $\mathrm{DC0206}$ & 5200 & 4400 & 31 & 10000 & 6000 & 7400 & 10700 & 1 & 0 & 6920 & 0.997 \\
\hline
\end{tabular}

NOTES:

1. 202: $I_{C h}$ from the second quench. The other plateau quenches originat $d$ in turn 13 .

2. 203: All plateau quenches originated in tum 15 .

3. The outer coil quenching observed in the training of some of the magnets persists also in the lower

temperature quenching tists of these magnets.

4. The fourth column indicates the value of $I^{2}$ beyond which the inner coil prestress is zero. For $I=6.5 \mathrm{kA}, I^{2}=42(\mathrm{kA})^{2}$. 


\section{REFERENCES}

1. A.K. Ghosh, M. Garber, K.E. Robins and W.B. Sampson, "Training in Test Samples of Superconducting Cables for Accelerator Magnets, " IEEE Trans. Magnetics 25:1831 (1989).

2. J. Kuzminski et al., "Test Results of BNL Built $40 \mathrm{~mm}$-Aperture, $17 \mathrm{~m}$-Long SSC Collider Dipole Magnets," IEEE Tians. Magnetics 28:311 (1992).

3. A. Devred et al., About the Mechanics of SSC Dipole Magnet Prototypes, in: "The Physics of Particle Accelerators," American Institute of Physics, NY (1992).

4. J.F. Muratore et al., "Construction and Test Results from $1.8 \mathrm{~m}$-Long, $50 \mathrm{~mm}$ Aperture SSC Model Collider Dipoles," paper to this conference (IISSC 92).

5. The outer coil quenches in DC0203 may not bear on the question of axial restraint, since all but three were near the location of the incorrectly-installed outer coil wedge (see Table I). The three quenches after the thermal cycle were far from this wedge. But the last two of these occurred near the warm end of the magnet when the temperature rise across the magnet was unusually high (100 mk versus $40 \mathrm{mk}$ ). 

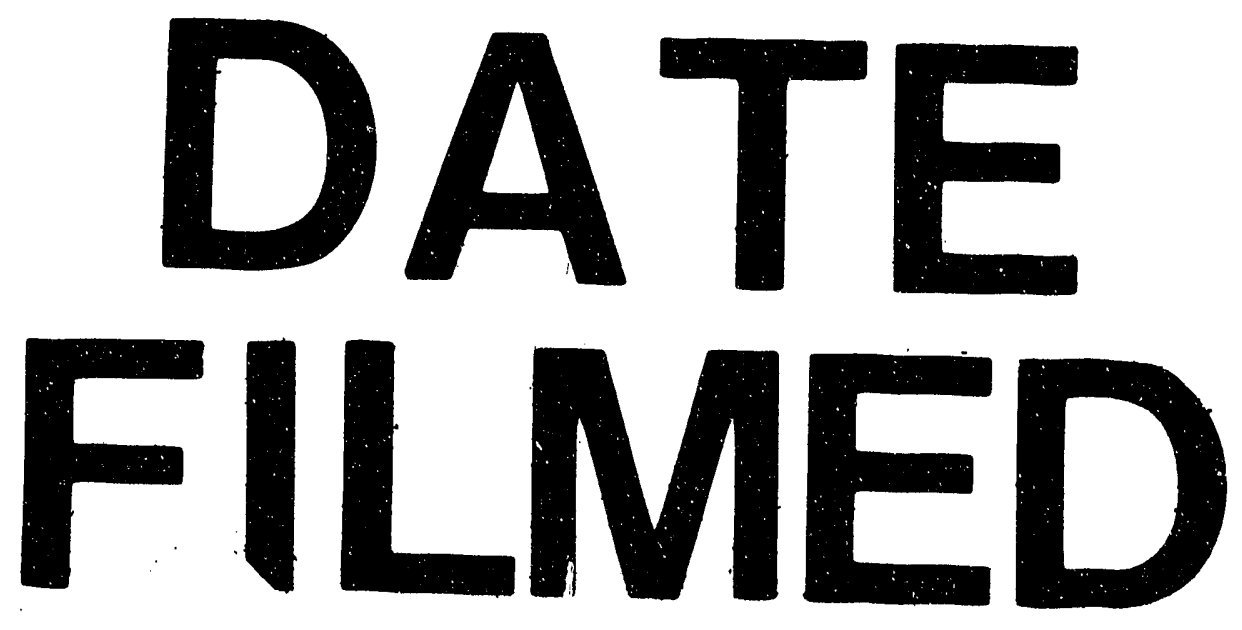

.

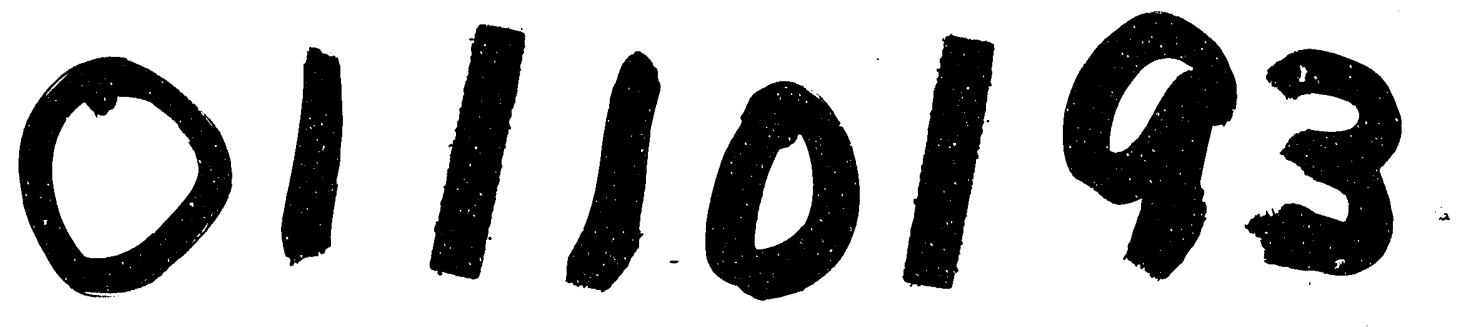


